\title{
The temporomandibular joint: pneumatic temporal cells open into the articular and extradural spaces
}

\author{
C. Bichir, M.C. Rusu, A.D. Vrapciu, N. Măru \\ "Carol Davila" University of Medicine and Pharmacy of Bucharest, Romania
}

[Received: 1 October 2018; Accepted: 22 November 2018]

\begin{abstract}
The pneumatisation of the articular tubercle (PAT) of the temporal squama is a rare condition that modifies the barrier between the temporomandibular joint (TMJ) space and the middle cranial fossa. During a routine examination of the cone-beam computed tomography (CBCT) files of patients who were scanned for dental medical purposes, we identified a case with multiple rare anatomic variations. First, the petrous apex was bilaterally pneumatised. Moreover, bilateral and multilocular PAT were observed, while on one side it was further found that the pneumatic cells were equally dehiscent towards the extradural space and the superior joint space. To the best of our knowledge, such dehiscence has not previously been reported. The two temporomastoid pneumatisations were extended with occipital pneumatisations of the lateral masses and occipital condyles, the latter being an extremely rare evidence. The internal dehiscence of the mandibular canal in the right ramus of the mandible was also noted. Additionally, double mental foramen and impacted third molars were found on the left side. Such multilocular PAT represents a low-resistance pathway for the bidirectional spread of fluids through the roof of the TMJ. Further, it could add to a morphological picture of hyperpneumatisation of the posterior cranial fossa floor, which could signify the involvement of the last four cranial nerves in the clinical picture of TMJ pain. (Folia Morphol 2019; 78, 3: 630-636)
\end{abstract}

Key words: temporomandibular joint, hyperpneumatisation, occipital bone, mandible, temporal bone, mental foramen

\section{INTRODUCTION}

The temporomandibular joint (TMJ) is a ginglymoarthrodial synovial joint, the most important functions of which are mastication and speech $[2,29]$. It also plays a key role in the orofacial system [29]. The articular surfaces involved in the TMJ include the mandibular fossa (MF) and the articular tubercle (AT) of the temporal bone, as well as the mandibular condyle. The bones that comprise the TMJ are covered with fibrous cartilage [29]. The human TMJ is subject to hugely variable stress due to the force resulting from the adductors of the jaw and masticatory pres- sure [39]. The prevalence of TMJ dysfunction has been shown to be increasing, so that it affects up to $28 \%$ of the adult population [16]. It has been suggested that morphological changes may be an important factor in relation to TMJ dysfunction [24]. However, the aetiology of TMJ pain is not yet fully understood, and discrepancies have also been found between imaging findings and patient symptoms [26].

The bones of the skull contain many air-filled cavities, which are referred to as pneumatisations [15]. Pneumatised spaces, or epithelial-lined air cell networks, are known to be ubiquitous in hominid temporal bones,

Address for correspondence: M.C. Rusu, MD, Dr. Med., Dr. Biol., Dr. Hab., Professor of Anatomy, "Carol Davila" University of Medicine and Pharmacy of Bucharest, Romania, e-mail: anatomon@gmail.com 
which means that pneumatisation features in many phylogenetic discussions and fossil descriptions [10].

The pneumatisation of the articular tubercle (PAT) is a term that describes the accessory air cells that occur in the root of the zygomatic arch, as well as in the articular eminence/tubercle of the temporal bone, which are similar to mastoid or ethmoidal air cells $[20,36]$. The PAT term was first used by Tyndall and Matteson [36] in their study concerning a series of orthopantomograms. Two subgroups of the PAT were identified, namely unilocular and multilocular $[17,36]$. Further, it has been determined that there are three stages involved in the pneumatisation of the temporal bone, namely infantile (birth to 2 years), transitional ( $2 \pm 5$ years) and adult [4].

During routine oral and maxillofacial radiology practice, portions of the base of the skull that include the temporal bone are visualised [13]. It is hence important for dentists and oral radiologists alike to be aware of common anatomical variations and pneumatisation patterns [13].

While retrospectively analysing the cone-beam computed tomography (CBCT) files of patients who were scanned for dental medical purposes, we observed a case with rare anatomic variations in addition to extensive temporal and occipital pneumatisations, which we report on here.

\section{MATERIALS AND METHODS}

A retrospective $C B C T$ study involving the archived files of 200 patients who were scanned for dental medical purposes was performed. The anatomical variation we report on here was encountered in a 42-year-old female patient. All the subjects had been scanned using an iCat CBCT machine (Imaging Sciences International) with the following settings: a resolution of 0.250 , a field of view of $130^{\circ}$ and an image matrix size of $640 \times 640$. The subjects were positioned according to the manufacturer's instructions. Using the iCatVision software, the CBCT data were exported as a single uncompressed DICOM file, which we further analysed using the Planmeca Romexis Viewer 3.5.0.R software. More specifically, we evaluated the two-dimensional (2D) multiplanar reconstructions (MPRs) in the three anatomical planes and the three-dimensional (3D) volume renderisations of specified areas using the "Soft Tissue" (in the Planmeca Romexis Viewer 3.5.0.R software) and "Bone/Teeth" (in the iCatVision software-related application three-dimensional volume renderisations [3DVR] v5.0.0.3) filters. The relevant anatomical features were exported as image files (*.tif). The subjects had all provided written informed consent that all their medical data (including radiographs, CBCT scans and intraoral images) could be used for research and teaching purposes, provided that their anonymity was preserved.

\section{RESULTS}

The subject reported on here presented an almost complete dentition. In fact, there were only three missing teeth, namely the first mandibular molars and the second right maxillary molar. The third molars were all formed, although only those on the right side had erupted. The left mandibular third molar exhibited a horizontal impaction, and it came into direct contact with the neurovascular bundle in the mandibular canal (due to the loss of the cortical lining of the canal). The left third maxillary molar was impacted in the maxillary tuberosity above the crown of the second molar (Fig. 1).

The occlusal contacts could not be properly evaluated because the $C B C T$ scan was not performed in the maximum intercuspidation condition. The subject's frontal maxillary and mandibular teeth were found to be in the protrusive position, and some imperfect contacts in relation to the posterior teeth (premature contacts or interferences) were also suspected due to the migrations of the remaining molars into the edentulous spaces.

The respective case study found extensive pneumatisations of the temporal bones, with the air spaces being extended bilaterally into the occipital bones. Further, each lateral mass of the occipital bones was pneumatised from the mastoid antrum and, additionally, extended within the occipital condyles. The pneumatisation of the left occipital condyle was more extended, both transversally and sagittally (Fig. 2). The air-filled occipital areas were found to be related to the hypoglossal canals and jugular foramina.

Bilateral multilocular pneumatisations of the AT were found within both the AT and the zygoma root (Figs. 3, 4). The petrous apex was also extensively pneumatised, in this case bilaterally. On the left side, the air cells within the AT were equally dehiscent superiorly towards the extradural space and inferiorly towards the superior space of the TMJ.

The complete dehiscence of the mandibular canal was noticed on the internal surface of the right mandible ramus, which truly became a canal when it entered the mandible body, as well as on the accessory foramina located beneath the mandible notch and above the lingula 


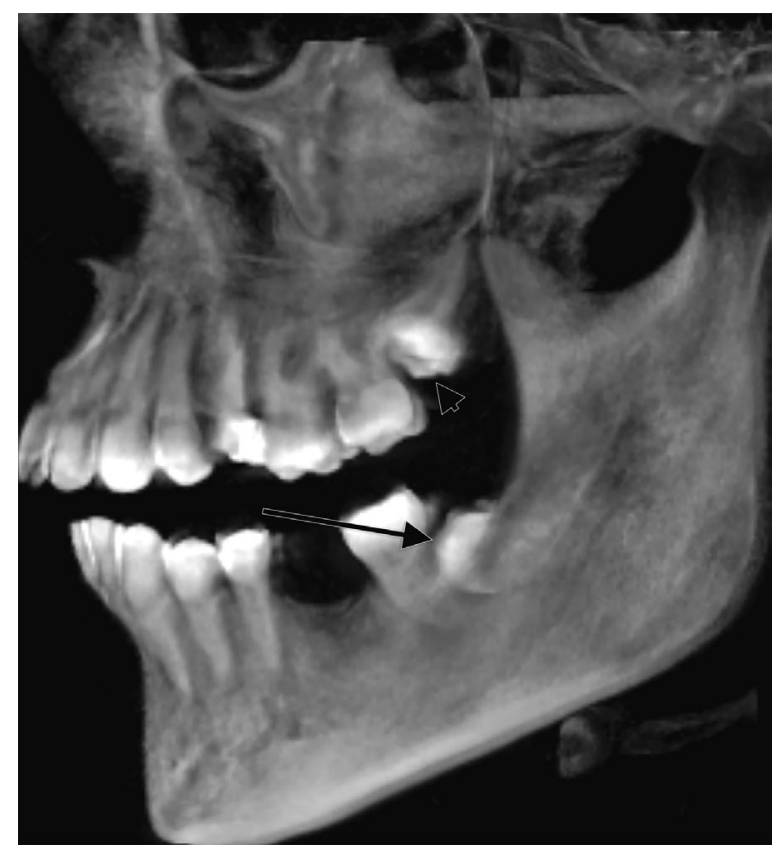

Figure 1. Three-dimensional volume renderisation, left view. Impacted third molars, maxillary (arrowhead) and mandibular (arrow), are present.

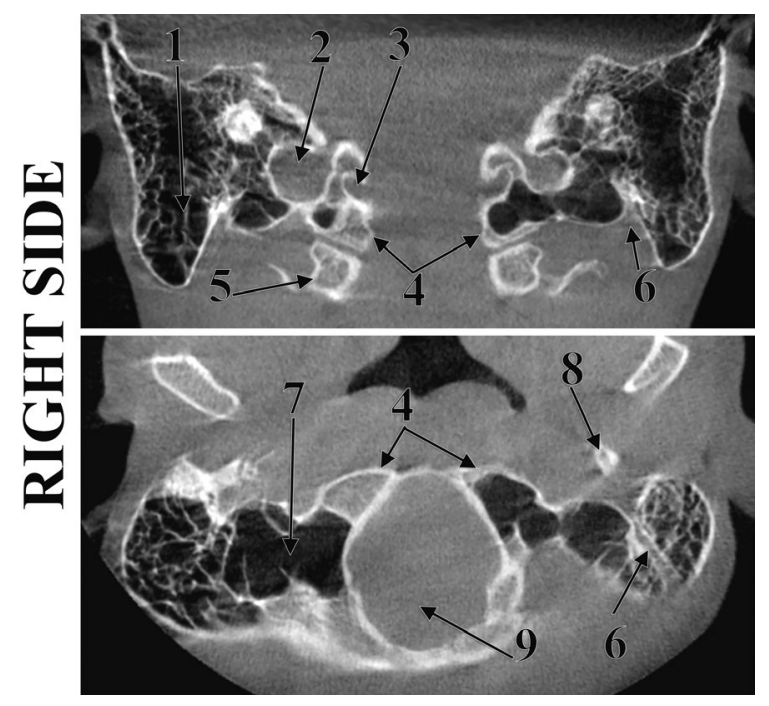

Figure 2. Coronal (upper panel) and axial (lower panel) multiplanar reconstructions depicting the bilateral pneumatised lateral masses of the occipital bones; 1 - mastoid air cells; 2 - sigmoid sinus; 3 - hypoglossal canal; 4 - occipital condyles; 5 - lateral mass of atlas; 6 - mastoid notch; 7 - pneumatised lateral mass of occipital; 8 - styloid process; 9 - foramen magnum.

(Fig. 5). We referred to the latter as "molar foramina", since they could supply the molar nerves or vessels.

Additionally, a double mental foramen was found on the left side, into which opened a mental canal that divided within the external cortical plate of the mandible body (Fig. 6).
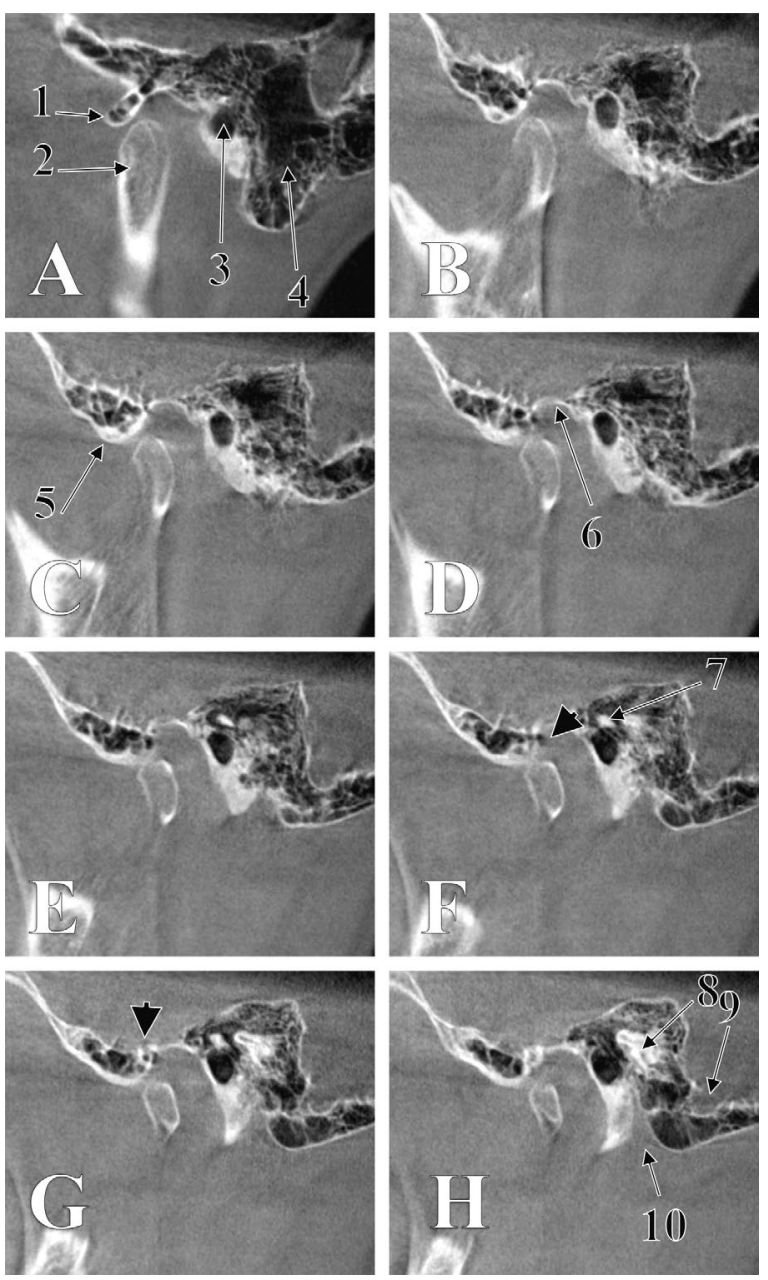

Figure 3. Lateral-to-medial series of sagittal multiplanar reconstructions (A-H) of the left temporomandibular joint (TMJ). Pneumatised articular tubercle with opened air cells; 1 - root of the zygomatic process; 2 - mandibular condyle; 3 - external auditory meatus; 4 - mastoid process; 5 - pneumatised articular tubercle; 6 - mandibular fossa; 7 - the attic/epitympanum; 8 semicircular canals; 9 - sigmoid sinus groove; 10 - facial nerve canal. The arrowhead in panel $\mathbf{F}$ indicates an air cell opened to the upper TMJ space, while the arrowhead in panel $\mathbf{G}$ indicates an air cell opening towards the extradural space.

\section{DISCUSSION}

Pneumatisation begins with the creation of small osseous cavities by means of normal periosteal activity. The bone marrow in these cavities then dedifferentiates into loose mesenchymal tissue into which the epithelium invaginates and produces a mucous membrane, which, in turn, undergoes atrophy and leaves a thin residual lining membrane attached to the periosteum [4]. The continued subepithelial bone resorption further expands the air cells, and pneumatisation ceases around puberty [4].

Various functions can be ascribed to the air cells of the ear, including facilitating the reception of sound, 


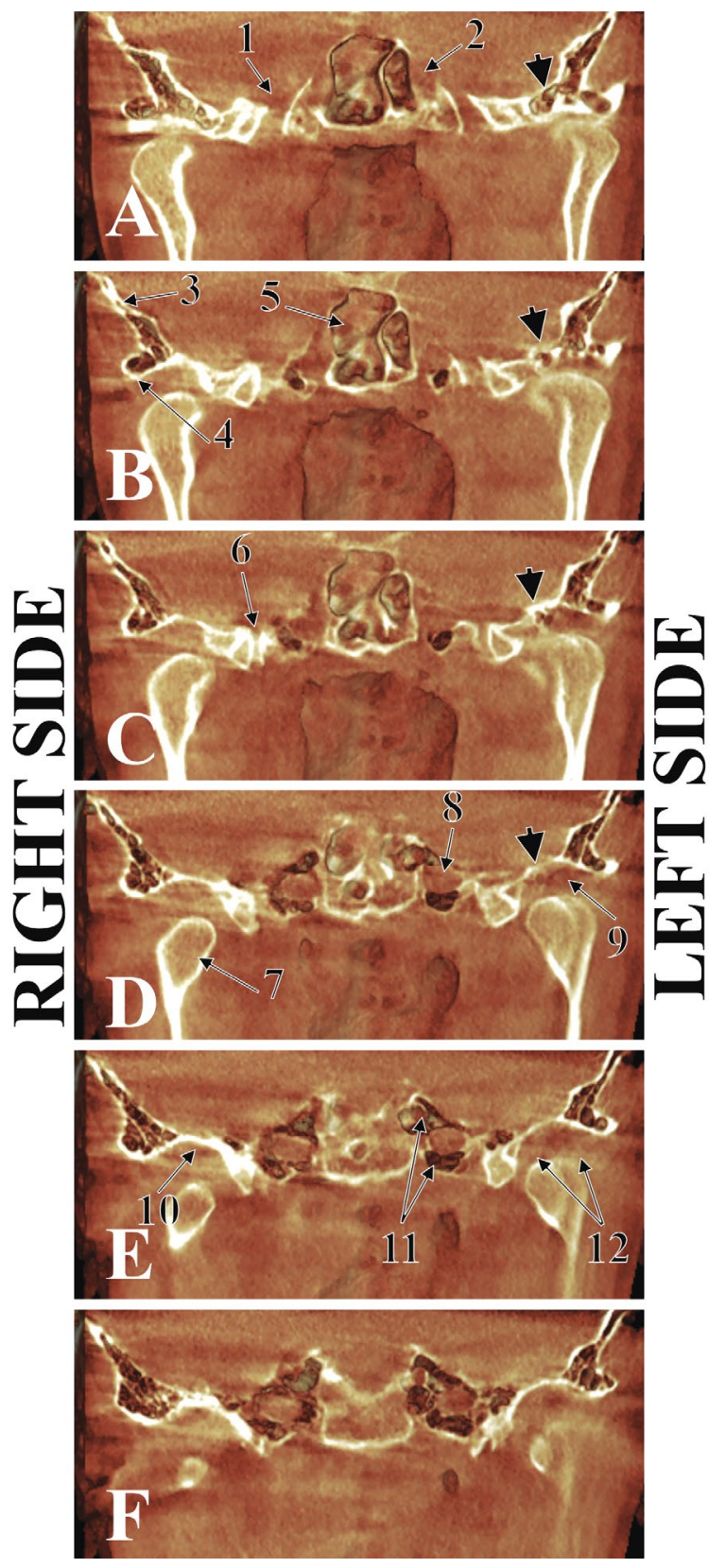

Figure 4. A-F. Anterior-to-posterior series of coronal three-dimensional volume renderisations. Bilateral temporomandibular joint (TMJ) study; 1 - foramen ovale; 2 - cavernous sinus; 3 - temporal squama; 4 - root of the zygomatic process; 5 - sphenoidal sinus; 6 - foramen spinosum; 7 - mandibular condyle; 8 - petrous apex, internal carotid artery; 9 - supradiscal space of the left TMJ; 10 - mandibular fossa; 11 - petrous apex air cells; 12 - TMJ disc. The arrowheads in panels $A$ to $D$ indicate an air cell within the articular tubercle that finally opens in the upper TMJ space.

resonance, insulation, air reservoir action and acoustic dissipation [34], as well as providing protection from external violence and reducing the weight of the skull [21].

The presence of pneumatic cells within the zygomatic arch and the squamous part of the temporal

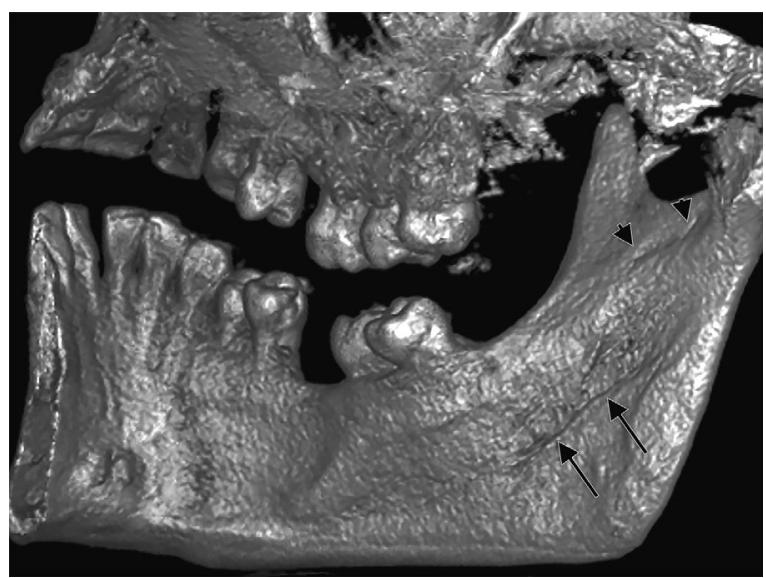

Figure 5. Three-dimensional volume renderisation depicting the internal surface of the right mandibular ramus. The identified molar foramina (arrowheads) and the dehiscent mandibular canal (arrows) can be seen.

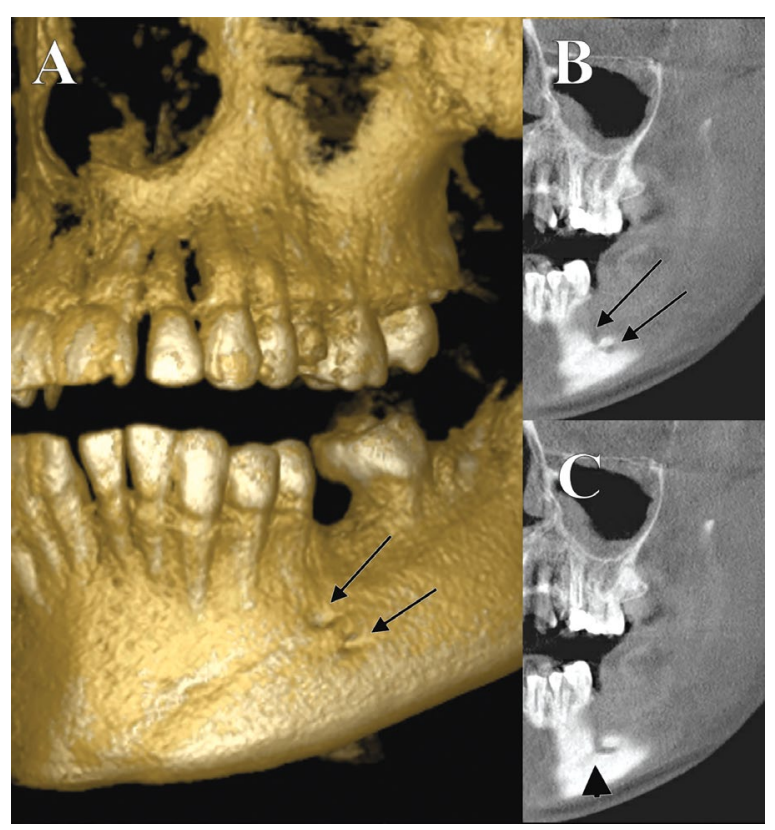

Figure 6. Three-dimensional volume renderisation $(\mathbf{A})$ and successive oblique/sagittal multiplanar reconstructions (B) and (C) of the left hemimandible, demonstrating the double mental foramen (arrows) that results from the bifurcation of the mental canal within the outer cortical of the mandibular body (arrowhead).

bone suggests the existence of a squamomastoid line for spreading the inflammatory/infectious pathology [33]. Such squamomastoid pneumatisation does not correlate with age, gender or laterality [38].

In a study involving 40 patients, the prevalence of the PAT was found to be $1.5 \%$, while a meta-analysis of three large case series indicated a prevalence of $1.7 \%$ [4]. A CBCT study involving 111 cases identified the PAT in $65.8 \%$ of individuals [12]. In a study performed 
on 514 cases, the authors found a PAT prevalence of $8.0 \%$, and they discussed how the PAT could actually be a more common condition than is generally recognised and, further, that in terms of differential diagnosis, panoramic radiographs should be supplemented with CBCT [17]. Moreover, no correlation was found between gender and the prevalence of pneumatisations of the temporal bone in relation to the TMJ [28].

Cone-beam computed tomography allows for the presurgical prediction of both the extent of the pneumatisation and the pathology [38]. A case report concerning a bilateral resective AT intervention represents a clear example of the importance of CBCT. After the drilling phase and the removal of the cortical bone on the right, a hollow AT was found and, based on the clinical examination and the postoperative computer-assisted axial tomography, it was concluded that a pneumatisation of the AT had not been identified in the $2 \mathrm{D}$ radiological examination conducted prior to the surgery. The major problem encountered during the intervention was the difficulty of re-obtaining a continuous articular surface for the condyle translation, which was solved by means of a free autologous graft [14]. Therefore, surgeons who are planning TMJ surgery should thoroughly assess the radiographic imaging in order to avoid intra-operative complications and reconstruction [20].

In cases of subjective or objective pulsatile tinnitus, a differential diagnosis is required. A 3D investigation can sometimes provide a straightforward diagnosis. A few case reports involving $C T$ investigations have associated pulsatile tinnitus with extended pneumatisation around the internal carotid artery [32, 35].

The association between temporomandibular joint dysfunctions (TMDs) and extended pneumatisation has yet to be proven, since the few case reports that included both the symptoms of a TMD syndrome and 3D radiological findings of the PAT appeared to be mere coincidences. Each TMD was treated according to the regular, conservative protocol, and the symptoms were relieved $[8,30]$.

Among the various possible sources of TMJ pain are disk displacement, osteoarthritis, bone marrow alterations in the mandibular condyle, inflammatory changes in the retrodiscal tissue and inflammatory changes in the joint space resulting in joint effusion [26].

The pneumatisation pattern can affect any surgical procedures involving the base region of the skull, since the air cells can postoperatively serve as sources of cerebrospinal fluid leakage [13].
The PAT is a low-resistance structure, which means that it is more likely to be exposed to trauma. The extensive temporal pneumatisation seen in patients with absent posterior dentition could represent a cause of the pathological intrusion of the mandibular condyle into the middle cranial fossa [40].

Fractures to the base of the skull extend throughout the pneumatic spaces of the temporal bone and hence may release air into the glenoid fossa [30]. Dehiscent air cells of the PAT, such as those we found, release air into both the extradural space and the TMJ superior space.

The location and course of the mandibular canal, as well as the location and number of the mental foramina, are important in relation to any surgical procedures involving the mandible [19]. The anatomical variability of the mental foramen should also be considered when performing periodontal or endodontic surgery in the area extending from the canine to the root of first molar tooth [7].

It is important to differentiate any additional (accessory) mental foramina from nutrient foramina, since the latter are unconnected to the mandibular canal [19, 37]. According to Igarashi et al. [11], the incidence of double mental foramina reported in the literature is approximately $6.9 \%$. However, a prevalence of $4.38 \%$ has also been reported [6]. The incidence of double mental foramina has been found to vary among different ethnic groups [27], and it could reach up to $10.8 \%$ [1].

Generally speaking, anaesthetic infiltrations of the inferior alveolar nerve are performed close to the mandibular lingula (the spine of Spix) in the pterygomandibular space [25]. The dehiscence of the internal wall of the mandibular canal, such as we found here, should serve to facilitate the procedure, although it could expose the neurovascular content of the canal to iatrogenic damage if the needle is directed towards the mandibular ramus.

The possibility of supplementary nerves entering the mandible was previously considered to be one potential cause of the lack of complete anaesthesia subsequent to its injection into an inferior alveolar nerve [9]. Accessory foramina on the medial aspect of the mandible, such as the molar foramina, could supply accessory innervation and/or collateral circulation to the posterior teeth [9]. Molar foramina of $6-10 \mathrm{~mm}$ in length have been found with a prevalence of $40 \%$ [3].

According to the American Association of Oral and Maxillofacial Surgeons (AAOMS), the "impacted 
teeth that demonstrate pathology, or are at high risk of developing pathology, should be surgically managed", although "in the absence of pathology or significant risk of pathology, active clinical and radiographic surveillance is indicated" [22].

The surgical removal of third molars represents one of the most frequently performed surgical procedures intended to treat pathoses that originate from impacted teeth [5]. During the extraction of maxillary impacted third molars, complications such as maxillary tuberosity fractures, oroantral communications or alveolar bone fractures could occur [5]. The removal of a mandibular impacted third molar places the inferior alveolar neurovascular bundle at risk.

In cases of well-pneumatised temporal bones, accessory occipital air cells may occur and, further, may communicate with the mastoid air cells and middle ear [18]. The pneumatisation of the occipital bone $(\mathrm{POB})$ is rare [18], despite being considered a normal variant [31]. The $P O B$ was investigated in 1000 CT scans and found to have a prevalence of $11.8 \%$ [31], although occipital condyle pneumatisation, such as we report on here, was only encountered in $0.5 \%$ of cases. Among the POB-positive cases, $21.2 \%$ were found to be bilateral, as in our case.

In our case, the occipital pneumatisation was found to be related to the jugular foramen and the hypoglossal canal. Thus, it appears that a certain pathological status involving the occipital air space could give rise to specific neurological signs, for example, within clinical pictures of TMD or related to otomastoid pathology. A pre-existing cranial bone pneumatisation places patients at risk of cranial bone fractures to the thinned bone [23]. Such minor trauma to the pneumatised occipital bone has been found to determine a unilateral hypoglossal palsy following a hypoglossal canal fracture [23].

\section{CONCLUSIONS}

A multilocular dehiscent PAT represents a low-resistance pathway for the bidirectional spread of fluids through the roof of the TMJ, and it could form part of a morphological picture of the hyperpneumatisation of the posterior cranial fossa floor, which could signify the involvement of the last four cranial nerves in the clinical picture of TMJ pain.

\section{REFERENCES}

1. Ahmed S, Jasani V, Ali A, et al. Double accessory mental foramina: report of an anatomical variant. Oral Surgery. 2015; 8(1): 51-53, doi: 10.1111/ors.12119.
2. Alomar X, Medrano J, Cabratosa J, et al. Anatomy of the temporomandibular joint. Semin Ultrasound CT MR. 2007; 28(3): 170-183, indexed in Pubmed: 17571700.

3. Barker BC, Lockett BC. Multiple canals in the rami of a mandible. Oral Surg Oral Med Oral Pathol. 1972; 34(3): 384-389, indexed in Pubmed: 4505752.

4. Carter LC, Haller AD, Calamel AD, et al. Zygomatic air cell defect (ZACD). Prevalence and characteristics in a dental clinic outpatient population. Dentomaxillofac Radiol. 1999; 28(2): 116-122, doi: 10.1038/sj/dmfr/4600424, indexed in Pubmed: 10522201.

5. Chiapasco M, De Cicco L, Marrone G. Side effects and complications associated with third molar surgery. Oral Surg Oral Med Oral Pathol. 1993; 76(4): 412-420, indexed in Pubmed: 8233418.

6. Gershenson A, Nathan H, Luchansky E. Mental foramen and mental nerve: changes with age. Acta Anat (Basel). 1986; 126(1): 21-28, indexed in Pubmed: 3739599.

7. Gupta S, Soni JS. Study of anatomical variations and incidence of mental foramen and accessory mental foramen in dry human mandibles. Natl J Med Res. 2012; 2: 28-30.

8. Hasnaini $\mathrm{M}, \mathrm{Ng}$ SY. Extensive temporal bone pneumatization: incidental finding in a patient with TMJ dysfunction. Dent Update. 2000; 27(4): 187-189, doi: 10.12968/ denu.2000.27.4.187, indexed in Pubmed: 11218454.

9. Haveman CW, Tebo HG. Posterior accessory foramina of the human mandible. J Prosthet Dent. 1976; 35(4): UNKNOWN, indexed in Pubmed: 1062606.

10. Hill CA. Ontogenetic change in temporal bone pneumatization in humans. Anat Rec (Hoboken). 2011; 294(7): 1103-1115, doi: 10.1002/ar.21404, indexed in Pubmed: 21618436.

11. Igarashi C, Kobayashi K, Yamamoto A, et al. Double mental foramina of the mandible on computed tomography images: a case report. Oral Radiology. 2004; 20(2): 68-71, doi: 10.1007/s11282-004-0012-1.

12. ilgüy $M$, Dölekoğlu $S$, Fişekçioğlu $E$, et al. Evaluation of pneumatization in the articular eminence and roof of the glenoid fossa with cone-beam computed tomography. Balkan Med J. 2015; 32(1): 64-68, doi: 10.5152/balkanmedj.2015.15193, indexed in Pubmed: 25759774.

13. Jadhav $A B$, Fellows $D$, Hand $A R$, et al. Classification and volumetric analysis of temporal bone pneumatization using cone beam computed tomography. Oral Surg Oral Med Oral Pathol Oral Radiol. 2014; 117(3): 376-384, doi: 10.1016/j.00oo.2013.12.398, indexed in Pubmed: 24528795.

14. Kulikowski BM, Schow SR, Kraut RA. Surgical management of a pneumatized articular eminence of the temporal bone. J Oral Maxillofac Surg. 1982; 40(5): 311-313, indexed in Pubmed: 6953185.

15. Ladeira DBS, Barbosa GLR, Nascimento MCC, et al. Prevalence and characteristics of pneumatization of the temporal bone evaluated by cone beam computed tomography. Int J Oral Maxillofac Surg. 2013; 42(6): 771-775, doi: 10.1016/j.ijom.2012.12.001, indexed in Pubmed: 23290566.

16. Laney TJ, Kaplan PA, Tu HK, et al. Normal and abnormal temporomandibular joints: quantitative evaluation of inferior joint space arthrography. Int J Oral Maxillofac Surg. 1987; 16(3): 305-311, indexed in Pubmed: 3112259. 
17. Miloglu $O$, Yilmaz AB, Yildirim E, et al. Pneumatization of the articular eminence on cone beam computed tomography: prevalence, characteristics and a review of the literature. Dentomaxillofac Radiol. 2011; 40(2): 110-114, doi: $10.1259 / \mathrm{dmfr} / 75842018$, indexed in Pubmed: 21239574.

18. Moreira B, Som PM. Unexplained extensive skull base and atlas pneumatization: computed tomographic findings. Arch Otolaryngol Head Neck Surg. 2010; 136(7): 731-733, doi: 10.1001/archoto.2010.108, indexed in Pubmed: 20644073.

19. Naitoh M, Hiraiwa $Y$, Aimiya $H$, et al. Accessory mental foramen assessment using cone-beam computed tomography. Oral Surg Oral Med Oral Pathol Oral Radiol Endod. 2009; 107(2): 289-294, doi: 10.1016/j.tripleo.2008.09.010, indexed in Pubmed: 19071039.

20. Orhan K, Delilbasi C, Cebeci I, et al. Prevalence and variations of pneumatized articular eminence: a study from Turkey. Oral Surg Oral Med Oral Pathol Oral Radiol Endod. 2005; 99(3): 349-354, doi: 10.1016/j.tripleo.2004.08.005, indexed in Pubmed: 15716844.

21. Proetz AW. Lxviii. Observations upon the formation and function of the accessory nasal sinuses and the mastoid cells. Ann Otol Rhinol Laryngol. 1922; 31: 1083-1099.

22. Rafetto LK. Managing impacted third molars. Oral Maxillofac Surg Clin North Am. 2015; 27(3): 363-371, doi: 10.1016/j. coms.2015.04.004, indexed in Pubmed: 26070801.

23. Renard D, Freitag C, Castelnovo G. Mystery case: hypoglossal nerve palsy in occipito-temporal pneumatization. Neurology. 2012; 79(13): e109-e110, doi: 10.1212/ WNL.0b013e31826c1b41, indexed in Pubmed: 23008226.

24. Rusu MC, Pop F, Leonardi R, et al. Morphologic features of the fetal mandibular condyle: layers, canals and microvascular pattern. Ann Anat. 2011; 193(5): 436-446, doi: 10.1016/j.aanat.2011.03.006, indexed in Pubmed: 21530206.

25. Rusu MC, Săndulescu M, Bichir C, et al. Combined anatomical variations: The mylohyoid bridge, retromolar canal and accessory palatine canals branched from the canalis sinuosus. Ann Anat. 2017; 214: 75-79, doi: 10.1016/j. aanat.2017.07.006, indexed in Pubmed: 28823708.

26. Sano T, Yamamoto M, Okano T, et al. Common abnormalities in temporomandibular joint imaging. Curr Probl Diagn Radiol. 2004; 33(1): 16-24, doi: 10.1016/j.cpradiol.2003.09.001, indexed in Pubmed: 14712198.

27. Sawyer DR, Kiely ML, Pyle MA. The frequency of accessory mental foramina in four ethnic groups. Arch Oral Biol. 1998; 43(5): 417-420, indexed in Pubmed: 9681117.

28. Shamshad MP, Kamath G, Babshet M, et al. Prevalence of temporal bone pneumatization in relation to temporomandibular joint. A computed tomographic study. J Stomatol Oral Maxillofac Surg. 2018; 119(2):
118-121, doi: 10.1016/j.jormas.2017.11.016, indexed in Pubmed: 29197682.

29. Stanković S, Vlajković S, Bošković M, et al. Morphological and biomechanical features of the temporomandibular joint disc: an overview of recent findings. Arch Oral Biol. 2013; 58(10): 1475-1482, doi: 10.1016/j.archoralbio.2013.06.014, indexed in Pubmed: 23871384.

30. Stoopler ET, Pinto A, Stanton DC, et al. Extensive pneumatization of the temporal bone and articular eminence: an incidental finding in a patient with facial pain. Case report and review of literature. Quintessence Int. 2003; 34(3): 211-214, indexed in Pubmed: 12731603.

31. Tomblinson CM, Deep NL, Fletcher GP, et al. Normal Variant Occipital Pneumatization. Otol Neurotol. 2018; 39(9): e872-e875, doi: 10.1097/MAO.0000000000001947, indexed in Pubmed: 30080763.

32. Topal O, Erbek SS, Erbek S, et al. Subjective pulsatile tinnitus associated with extensive pneumatization of temporal bone. Eur Arch Otorhinolaryngol. 2008; 265(1): 123-125, doi: 10.1007/s00405-007-0400-3, indexed in Pubmed: 17647005.

33. Tremble GE. Pneumatization of the temporal bone. Arch Otolaryngo Head Neck Surg. 1934; 19(2): 172-182, doi: $10.1001 /$ archotol.1934.03790020018002.

34. Tumarkin A. On the nature and vicissitudes of the accessory air spaces of the middle ear. J Laryngol Otol. 1957; 71(2): 65-99, indexed in Pubmed: 13406420.

35. Tüz $M$, Doğru H, Yeşildağ A. Subjective pulsatile tinnitus associated with extensive pneumatization of temporal bone. Auris Nasus Larynx. 2003; 30(2): 183-185, indexed in Pubmed: 12753991.

36. Tyndall DA, Matteson SR. Radiographic appearance and population distribution of the pneumatized articular eminence of the temporal bone. J Oral Maxillofac Surg. 1985; 43(7): 493-497, indexed in Pubmed: 3859592.

37. Vasconcelos TV, Sampaio Ne, Haiter-Neto F, et al. Double mental foramina. Revista Cubana de Estomatologia. 2013; 50: 443-448.

38. Virapongse C, Sarwar M, Bhimani S, et al. Computed tomography of temporal bone pneumatization: 1. Normal pattern and morphology. AJR Am J Roentgenol. 1985; 145(3): 473-481, doi: 10.2214/ajr.145.3.473, indexed in Pubmed: 3875250.

39. Werner JA, Tillmann B, Schleicher A. Functional anatomy of the temporomandibular joint. A morphologic study on human autopsy material. Anat Embryol (Berl). 1991; 183(1): 89-95, indexed in Pubmed: 2053712.

40. Wilson C, Iwanaga J, Oskouian RJ, et al. Anatomical Examination of Mandibular Condyle Protrusion Into the Middle Cranial Fossa. J Craniofac Surg. 2018; 29(4): 1069-1071, doi: $10.1097 /$ SCS. 0000000000004425 , indexed in Pubmed: 29543680. 